\section{ON A CASE OF OVARIAN DROPSY.}

INJECTION OF TEE CYST WITH TINCTURE OF IODINE; CURE.

BY C. BLACK, M.D. LOND., F.R.C.S.

R. M- - a young lady of nervo-bilious temperament, at the age of twenty perceived, for the first time, that her abdomen was somewhat larger than natural. The enlargement was not confined to either side; but it manifested itself by a greater fulness of the abdomen generally, which obliged her to "let out" her different articles of cliess. She had never suffered any pain or uneasiness in any particular part of the abdomen; her general health had hitherto been good; but menstruation had, for a short time of late, returned at the end of every third week. This continued from four to five days; but the quantity of discharge was not greater than at the period of menstrual regularity. For eighteen months no medical opinion was sought, during which time the abdomen slowly but steadily enlarged. The general health still remained good; but menstruation, instead of returning at the end of the third week, now observed its natural period. Her own anxiety, as well as that of her friends, having at length been awakened by her present condition, she placed herself under the care of a physician, who at first treated her for hepatic enlargement, and subsequently regarded her case as one of pregnancy. The latter opinion caused her to seek the advice of another, by whom she was treated for mesenteric disease. Nine months from the com. mencement of medical treatment the case passed into my hands.

At this time the abdomen was equally distended, and as large as at the sixth month of pregnancy; the umbilieus was filling up; the abdominal walls could be lifsed, as it were, from the tumour beneath; and the recti muscles started prominently forth in the effort to raise herself from the supine to the sitting posture. Palpation, with the hands placed on opposite points of the abdomen, elicited a sensation of fluctuation; whilst, by deep pressure in the right iliac fossa, a solid mass of small size was indistinctly perceived. The os uteri had undergone no change, nor was it deflected to either side. Menstruation was regular, the general health was good, and nothing more than a feeling of weariness followed her usual amount of exertion.

The diagnosis at which I arrived was, that the case was one of ovarian dropsy; that the cyst sprang from the right ovary; that it was unilocular, and that as yet it had not, in all probability, acquired any adhesions to the abdominal walls or viscera. I was determined to watch the case, and to interfere as soon as the general health began to fail, or the function of any im. portant organ was compromised. About this time she paid a visit to Manchester, where, at my request, she availed herself of the great experience of Dr. Clay in such matters. His opinion being in strict accordance with my own, and both of us agreeing that there could not be a more favourable case for treatment by iodine injection, it was resolved to await the de. velopment of the above-mentioned conditions which should call for immediate interference. Twenty-one months elapsed before operative procedure was deemed necessary. During this time the disease gradually progressed, until at length the abdomen was so distended that the breathing became oppressed, the digestive function impaired, the nutrition of the body defective, and the nervous system irritable.

On September 20th, 1858, the operation of injecting the sac was resorted to. The bow els having been relieved by an aperient administered the day before, the patient was placed sitting in a chair, the abdomen was encircled with a broad bandage; a small opening was made in this at the point selected for puncture, and through it the skin of the abdomen having been divided by a lancet to the extent of an inch midway between the umbilicus and pubes, a large-sized trocar was pushed into the sac. The instrument was introduced as far as possible, and its point directed slightly upwards, in order that the sac might, during its collapse, be hooked upon the point of the canula, and thus ensure the introduction of the injection into its cavity. Fifteen pints of a clear, pale, straw-coloured fluid, of the specilic gavity of 1.022 , and highly albuminous, were withdrawn. As the sac was being emptied the body was gradually inclined forwards, to maintain the relative position of the former to the canula. Twelve ounces of the Edinburgh tincture of iodine were now thrown into the sac by means of an enema apparatus, the pipe of which had been accurately adapted to the tube of the canula. The fluid was retained exactly twenty minutes, and the whole, or nearly the whole, of it was returned through the canulia as readily as the original fluid of the sac was withdrawn. The injection had, therefore, reached its proper place. Fifteen minutes after the injection had been thrown into the sac, a severe paroxysm of hysteria supervened, during which the operation was completed, and the patient put to bed. Shortly after being put to bed, she became more calm; and, half an hour after this, the hysteria entirely ceased. During this time an opiate was administered and the room darkened. To relieve vomiting, which occurred immediately after the completion of the operation, and which returned at short intervals, an effervescent saline daaugh was occasionally given. Before the operation, the pulse was 70 , soft, regular, and equal; immediately after the operation it was 95 , small and feeble, but regular and equal. On my taking leave of her for a short time, strict orders were given to the nurse to employ incessant fomentations of hot poppy decoction should pain in any part of the abdomen arise. Evening: Has slept at intervals since the operation, but only for a few minutes together; sleep broken by sudden starts; ab. domen feels "sore," and there is general tenderness on pressure; skin hot and dry; countenance suffused; tongue dry, white at the edges, brown in the centre; thirst; pulse 130 , small, not wiry; respirations 23 per minute; sickness abated; has passed about four ounces of highly-coloured urine. Iodine not detectable in any of the secretions. She was ordered three grains of calomel and fifteen grains of Dover's powder, to be taken directly, and to be followed every third hour by two drachms of the solution of the acetate of ammonia, one-six. teenth of a grain of tartar emetic, and half a drachm of the spirit of nitrous ether, in the form of draught, together with a pill containing one grain of the grey powder and two grains of Dover's powder. The abdomen was to be frequently fomented during the night, and to be covered in the intervals by a hot linseed-dust poultice. The diet was to consist of groat-gruel, weak tea, and toast-water.

21st. - Eight o $0^{9}$ clock A. M. : Slept uninterruptedly from twelve to two this morning, and from the latter hour until six at short intervals. The abdomen is generally tender on pressure, but most so in the right inguinal region, in which the ovarian sac can be felt partially contracted, extending laterally a little beyond the linea alba, and upwards about an inch above the anterior superior spinous process of the ilium. Pulse 130 , small, soft, and regular; tongue still dry, and covered with a brown fur along the centre of its dorsum; thirst urgent; shin. hot and dry; has passed about six ounces of clear, highly. coloured urine. To continue the draught every third hour, and to take with it a pill containing one grain of calomel and two grains of Dorer's powder. The fomentations and poultices to be continued.-Evening: The pain of the abdomen has gradnally subsided duing the day; pulse 125 , larger; tongue moist at the tin and edges; thirst less urgent; skin disposed to perspire; has passed urine several times in increased quantity; bowels not moved since the operation. The remedies to be continued.

22nd.--Eight o'clock A.M. : Has passed a comfortable night, sleeping nninterruptedly two hours at once. The general "soreness" of the abdomen is much diminished. The ovarian. sac is very distinctly telt through the abdominal walls; it is less in size. Pulse 10s; tongue moist; thirst less; skin bathed in perspiration; respirations 19 per minute; urine deposits a heavy sediment of the nrates; bowels have not been moved since the operation. To continue the remedies, and to take an aperient draught, containing the sulphate and carbonate of magnesia, camphor mixture, and peppermint-water.-Evening: Bowels have acted freely several times during the day; she feels in every respect better.

23rd. - Has had a good night; pressure upon the abdomen gives little or no pain, except over the sac, where deep pressure produces manifest uncasiness; the sac is more reduced in size; pulse 110; tongue moist, but furred as before; thirst moderate; skin perspiring; bowels have not acted since last evening; urine (from twenty to thirty ounces in the twenty-four hours) deposits a sediment of urates.

Henceforth the patient progressed, under certain modifications of the above treatment, to convalescence on the ninth day after the operation, and thenceforward she entered upon a tonic plan of treatment, with the allowance of a more liberal 
diet. About this time she was permitted to leave her bed, and to sit up for a short time in her room. To obviate a sensa. tion of "a want of support" in the back and abdomen, a broad flannel bandage was applied, from which she derived great comfort, and which she continued to wear with advantage for several months after recovery. On the twenty-first day after the operation she left Chesterfield for her own residence. For several days before her departure not the slightest trace of the cyst could be detected on the most careful nanipulation. She has since continued well, and she is now in as robust health as at any period of her life. The abdomen has returned to its proper size, menstruation is perfect, and the eschar at the seat of puncture alone remains in expression of the disease from which she has suffered and of the operation which she has undergone.

Remarks. - The result of the above case affords proof of the value of iodine injection in the treatment of ovarian cysts. It will assist in determining the as yet undecided question as to the particular plan of treatment which oucht to be adopted in ovarian disease requiring operative interference. So far, then, it shows that, where the cyst is unilocular and unconnected with any malignant formation, or simple solid mass of any magnitude, the operation of injection of iodine is sufficient to effect a cure. The question upon this fact arises, as to the relative mortality of this operation to that which is best understood by the term "ovariotomy." If, under like circumstances, the former is followed by a les. mortality than the latter, it is surely the operation to be preferred in similar cases to the above. Statistics, however, are wanting, not to establish the propriety of either the one or the other operation, which seeros to be conceded by the all but unanimous voice of the profession, but to enable us to determine which operation is the more successful in the treatment of simple ovarian eysts. Facts have of late spoken strongly in favour of iocline injection, and to this mode of treatment $\dot{a}$ prior $i$ reasoning would tend. But there are, in this operation, risks to encounter which some authors think scarcely inferior to those which attend ovariotomy. The operation is followed by shock, by infammation of the eyst as the immediate result of the operation, and sometimes by uncontrollable peritonitis. If by accident the injected fluid is deposited in the peritoneal cavity, the last-mentioned condition is almost certain to arise. Where, too, the operator prefers leaving the injection within the cyst to be absorbed, a certain iodism of the system results, which may endanger and even destroy life. Against these occurrences, therefore, the operator must take every precaution. If shock occur before the opera. tion has been completed, it should be terminated as quickly as possible, because further persistence might induce immediate death. The system should likewise be supported by those means which refresh and sustain the powers of life. If the necessary inflammation excited in the cyst should threaten to extend beyond its legitimate bounds, it must be restrained by appropriate measures. To guard against the possibility of depositing the injection in the peritoneal cavity, and of thus exciting fatal peritonitis, the canula should be pushed as far as possible into the cyst with its point directed somewhat upwards, in order that the cyst may not, during its collapse, fall away from the canula and the abdominal puncture. If peritonitis arise, it should be met with promptitude upon the ordinary principles involved in the treatment of simple inflammation. To avoid iodisin and the danger attendant thereon, the injected thid should be withdrawn after having been retained a sufficient length of time. There is, in my opinion, no advantage to be cained by leaving it in the sac to be absorbed. The saturation of the system by iodine may clestroy life; but it can effect no more, in a curative point of view, than does the limited retention of the injection within the cyst.

Reviewed in some of these particulars, it will be seen that shock, in the character of hysteria, supervened at the expiration of fifteen minutes from the commencement of the operation, and that an early disposition to inflammation, not only of the cyst itself, but also of the peritoneum, followed its completion. The kigh rate of the pulse in the evening of the day of operation, its particular character of softness and compressibility, and the already dry, brown tongue, showed too plainly the tendency of the inflammation to assume an adynamic form. Active depletory measures were therefore uncalled for, and consequently unemployed. But with these symptoms were others : as the hot and dry skin; the red, injected countenance; the perfect stability of mind; the easy and but slightly accelerated breathing; the unimpaired physical power; and the deep, brisht, lively expression in the colour of the urine: which told me that present treatment ought not to embrace the use of stimulants. On the one hand, then, I endeavoured not to favour this adynamic tendency by loss of blood; and on the other, to avoid any additional excitement of the system by the use of remedies. The complete success which attended the case shows that these objects were attained, and that the further treatment of ovarian cysts by the means above stated, merits the particular attention of the nrofession.

Chesterfield, Sept. 1859.

\section{ON CASES OF GUN-SHOT FRACTURE.}

\section{BY H. D. FOWLER, FisQ.,}

SURGEON TO THE 82ND REGTMRNT, SHAHJEHANPORE.

A RECENT number of THE LANCET (April 23rd) contains some valuable remarlss on the subject of compound fracture in the upper extremity, by Mr. Skey. The following cases seem to me to illustrate the remark of that gentleman-namely, "The more experience we accuire, the firmer should be our reliance on the boundless resources of nature."

On the 3rd of May, 1858, the head-quarter companies of her Majesty's 8 2ud Regiment at Shahjehanpore were rather suddenly attacked by an overpowering force of the enemy, and obliged to retreat within the defences afforded by the ruins of the Jail, where they were shut up for eight cays, under a heavy fire from the rebels. It was in protecting this retreat that Private A. G- received a musket-wound in the left arm. The ball entered about three inches below the shoulderjoint, on the anterior surface, but somewhat towards its inne side, and passing across, obliquely outwards and downwards, extensively fractured and splintered the humerus, making its exit about three inches lower down, near the insertion of the deltoid. The large vessels and nerves were fortunately uninjured, and there was but little hæmorrhage or constitutional shock at the time; nor was the arm itself much displaced. The first question was as to amputation. The arm was badly fractured - the fracture possibly running up into the neighbouring joint; the bone, at all events, extensively comminuted, and a considerable extent of soft parts implicated and disorganized by the track of the ball. The contingent circumstances promised little in the way of rest and quiet. The patient, however, possessed a good constitution; and, having observed the superior vitality of the npper extremity, in its recovery from severe gun-shot injury, during the operations about Cawnpore, I determined on conservancy. Some spicule of bone were remover-one upwards of an inch and a half in length; the arm was slightly extended; the fracture adjusted as well as circumstances would permit, and lightly confined by two side splints; the forearm bent and confined, and water dressing applied. About the fourth day, an attack of erysipelas, with considerable swelling and pyrexia, supervened - yielding, however, readily to mild antiphlogistic remedies, and warm spirit lotion, \&c.; and was succeecied by a healthy discharge from the wounds. Througlout the treatuent, though he was repeatedly moved, no unfavourable symptoms occurred. His strength was well supported. From time to time, some small spiculre of bone and portions of the bullet were removed, while the discharge gradually diminished, and the wounds healed. $\mathrm{He}$ was sent home in October following, having been some time convalescent; the bone well united, and motion gradually returning in the joints of the elbow and fingers, which were somewhat contracted by long confinement; with every prospect of an arm nearly as efficient as betore the injury.

Thenativesplints are worth a momeni s notice, as easily adapted to the emercencies of military su' ery, and being simple and efficient. They consist of thin sulps of bamboo (other wood would do as well), about half an inch wide, and in length corresponcling to the limbs. Laced toretber with twine, and having intervals of about a quarter of an inch between each piece, the whole forms a light, efficient, and easily-adapted splint, through which discharge easily escapes.

Najor M-, Bengal Artillery, was handed over to me with the rest of the sick and wounded of the force under Lord Clyde at Futtehghur, when his Excellency proceeded thence to the capture of Lucknow; the major having been wounded several days previously at the passage of a river, on the advance upon the rebel camp at Futtehghur. The account handed over to me was of the most formidable and unpromising nature, -namely, a gun-shot wound, the ball entering the lower and anterior surface of the lef thigh just above the patelli, fracturing the femur, and involving most probably the joint, as synovia-like fluid oozed from the wound at the time of its infliction, the ball itself lying imbedded in the popliteal space, whence an in- 